Jurnal SPORTIF: Jurnal Penelitian Pembelajaran

Vol. 6 No. 1, April 2020, pp. 226-241

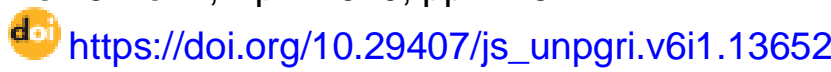

\title{
Pendekatan bermain sebagai solusi mengenalkan teknik dasar sepak takraw
}

\section{Approach to play as a solution introducing basic techniques} sepak takraw

\author{
Wing Prasetya Kurniawan ${ }^{1} \&$ Mokhammad Firdaus ${ }^{2}$
}

1,2Departemen Physical Education, Health, and Recreation, Universitas Nusantara PGRI Kediri, JI. KH. Achmad Dahlan No 76, Mojoroto District, Kediri, East Java Province, 64112, Indonesia

Received: 9 September 2019; Revised: 5 April 2020; Accepted: 17 April 2020

\begin{abstract}
Abstrak
Penelitian ini bertujuan untuk menghasilkan model pengenalan teknik dasar sepak takraw melalui pendekatan bermain untuk anak sekolah dasar kelas atas. Penelitian ini dilakukan dengan mengadaptasi 8 langkah-langkah penelitian Borg \& Gall, langkah-langkah tersebut antara lain: (1) pengumpulan informasi lapangan, (2) analisis informasi yang telah dikumpulkan, (3) mengembangkan produk awal, (4) validasi ahli dan revisi, (5) uji coba lapangan skala kecil dan revisi, (6) uji coba lapangan skala besar dan revisi, (7) pembuatan produk final, (8) uji efektivitas produk. Uji coba skala kecil dilakukan terhadap 22 anak sekolah dasar kelas atas (SDN Sukorejo 01). Uji coba skala besar dilakukan terhadap 82 anak sekolah dasar kelas atas (SDN Bendogerit 02, SDN Gedog 02, dan SDN Sentul 01). Instrumen yang digunakan untuk pengumpulan data adalah pedoman pengamatan, wawancara, catatan lapangan, skala nilai, lembar penilaian uji efektivitas, dan penilaian hasil belajar. Hasil penelitian ini berupa model pengenalan teknik dasar sepak takraw melalui pendekatan bermain, yang berisikan 5 model permainan berdasarkan teknik dasar sepak takraw dan disusun dalam bentuk buku panduan permainan. Dari hasil penilaian para ahli materi dan praktisi, dapat ditarik kesimpulan bahwa model pengenalan teknik dasar sepak takraw melalui pendekatan bermain untuk anak sekolah dasar berkategori baik dan efektif, sehingga model permainan layak untuk digunakan.
\end{abstract}

Kata kunci: bermain, pendidikan jasmani, pengembangan model, sepak takraw.

\begin{abstract}
This study aims to produce a model of introduction to the basis of sepak takraw basic techniques through a play approach for elementary school children of upper class. This research was carried out by adapting the 8 steps of the Borg \& Gall research, these steps include: (1) gathering field information, (2) analyzing the information that has been collected, (3) developing initial products, (4) expert validation and revisions, (5) small-scale field trials and revisions, (6) large-scale field trials and revisions, (7) manufacturing of final products, (8) product effectiveness tests. A small-scale trial was carried out on 22 upper-grade elementary school children (SDN Sukorejo 01). A large-scale trial was conducted on 82 high school elementary school children (SDN Bendogerit 02, SDN Gedog 02, and SDN Sentul 01). The instruments used for data collection were observation guidelines, interviews, field notes, value scales, effectiveness test assessment sheets, and assessment of learning outcomes. The results of this
\end{abstract}

Correspondence author: Wing Prasetya Kurniawan, Universitas Nusantara PGRI Kediri, Indonesia. Email: wingprasetya@unpkediri.ac.id

Jurnal SPORTIF: Jurnal Penelitian Pembelajaran is licensed under a Creative Commons Attribution-ShareAlike 4.0 International License. 
study are in the form of an introduction to the basic techniques of sepak takraw through a play approach, which contains 5 game models based on the sepak takraw basic techniques and arranged in the form of a game manual. From the results of the assessment of material experts and practitioners, it can be concluded that the introduction of the sepak takraw basic techniques through the play approach for elementary school children is categorized as good and effective, so that the game model is feasible to use.

Keywords: games, model development, physical education, sepak takraw.

\section{PENDAHULUAN}

Permainan sepak takraw merupakan permainan yang menarik untuk diajarkan di sekolah dasar. Hal ini dikarenakan permainan sepak takraw dilakukan dengan gerakan yang atraktif. Gerakan-gerakan tersebut menjadi daya Tarik siswa untuk bermain sepak takraw. Namun dalam pembelajaran, permainan sepak takraw membutuhkan pemahaman dan penguasaan materi. Penyusunan rencana pembelajaran wajib dilakukan oleh seorang guru pendidikan jasmani, agar proses pembelajaran berjalan dengan lancar dan sesuai dengan tujuan yang ingin dicapai. Mohnsen (2008) menyatakan bahwa pencapaian yang harus dicapai guru pendidikan jasmani yaitu mempunyai pemahaman menyeluruh tentang dasar-dasar pendidikan jasmani dan pemahaman yang luas terhadap prinsip dan teori-teori. Hal senada disampaikan oleh Chueachot, SrisaArd, \& Srihamongkol (2013) bahwa model pembelajaran yang berkualitas harus mempunyai komponen yang dapat menjadikan siswa belajar mandiri, dapat mengatur diri sebagai pelajar dan dapat berprestasi.

Melalui permainan sepak takraw, diharapkan akan tercapai tujuan pendidikan jasmani di sekolah dasar yaitu untuk mengembangkan aspek kognitif, afektif, dan psikomotor kepada siswa. Kurdi \& Sukadiyanto (2014) menyatakan bahwa pembelajaran motorik merupakan salah satu bagian dari pembelajaran pendidikan jasmani di sekolah, yang dibebankan tanggung jawab untuk mencapai tujuan pembelajaran agar anak memiliki keterampilan gerak yang memadai, sekaligus mengembangkan aspek kognitif, aspek fisik, dan aspek sosial. Hal senada dikemukakan Payne \& Isaacs (2011) bahwa aktivitas jasmani sangat berpengaruh terhadap perkembangan kognitif siswa dalam 
meningkatkan kemampuan mengingat dan membantu mempercepat pemrosesan informasi.

Dalam melaksanakan pembelajaran, Diperlukan strategi pengajaran yang bertujuan agar pembelajaran lebih menarik dan membuat siswa senang untuk melakukan gerak. Simamora (2009) menyatakan bahwa pembelajaran yang efektif dan efisien merupakan suatu konsep yang mencakup faktor eksternal dan internal seseorang dalam menyikapinya sehingga sesuai dengan keberhasilan pembelajaran atau tingkat pencapaian tujuan dari pembelajaran. Pembelajaran yang membosankan pada siswa sekolah dasar akan menyebabkan menurunnya motivasi untuk terlibat dalam pembelajaran pendidikan jasmani (Sun, 2013).

Strategi pembelajaran yang menarik agar siswa termotivasi untuk bergerak salah satunya adalah melalui pendekatan bermain. Permainan merupakan salah satu model pembelajaran yang dapat menunjang pertumbuhan dan perkembangan anak secara optimal. Menurut Juniarta \& Siswantoyo (2014) menyatakan bahwa bermain merupakan sarana penting dalam mengembangkan kemampuan jasmani anak, selain juga terdapat banyak nilai-nilai yang lain. Ngatiyo (2008) menyatakan bahwa melalui bermain anak dapat memetik manfaat dari perkembangan aspek fisik motorik, kecerdasan, dan sosial-emosional.

Berdasarkan hasil studi pendahuluan yang dilakukan di beberapa sekolah dasar yaitu SD Negeri Sukorejo 1, SD Negeri Bendogerit 2, SD Negeri Gedog 2, dan SD Negeri Sentul 1 di Kota Blitar, terungkap permasalahan yang dihadapi guru pendidikan jasmani terkait dengan pembelajaran sepak takraw. Sarana dan prasarana untuk bermain sepak takraw yang belum dimiliki sekolah merupakan masalah pertama, sehingga modifikasi sarana dan prasarana diperlukan dalam proses pembelajaran agar tujuan dari pembelajaran dapat tercapai (Zetou et al., 2014). Kedua, guru masih beranggapan bahwa dalam menerapkan pembelajaran sepak takraw identik dengan olahraga yang sesungguhnya sehingga bentuk kegiatan yang diberikan bersifat baku sesuai dengan 
olahraga resmi. Hal ini diperkuat dengan pernyataan John Wiley \& Sons (2012) bahwa salah satu motivasi yang paling tepat adalah dari pelatih atau guru, motivasi diperlukan untuk dorongan melakukan sesuatu yang disebabkan oleh ketertarikan pada suatu tujuan sehingga timbul suatu respon bentuk tampilan kegiatan, sehingga siswa tertarik mengikuti proses selanjutnya. Ketiga, kesulitan yang dihadapi guru adalah mengembangkan penilaian dari pembelajaran sepak takraw. Pentingnya tes yaitu untuk mengetahui dan mengevaluasi kemampuan siswa dalam proses pembelajaran. Datta \& Purashwani (2010) mengatakan bahwa tes keterampilan untuk membantu guru dalam mengevaluasi peningkatan kinerja siswa.

Penelitian Kurdi \& Sukadiyanto (2014) menyimpulkan bahwa model pembelajaran motorik dengan pendekatan bermain menggunakan agility leader untuk anak sekolah dasar kelas bawah dinilai baik dan efektif, sehingga model pembelajaran yang dikembangkan layak untuk digunakan. Utami \& Sukadiyanto (2014) menghasilkan model pengenalan air melalui aktivitas bermain bagi siswa TK kelompok B. Hasil penelitian berupa model pengenalan air bagi siswa TK yang terdiri dari 6 permainan, yaitu bola warna, air tumpah, harta karun, mandi pagi, hewan laut, dan balap donat dan kacang. Penelitian yang dilakukan oleh Ardiyanto \& Sukoco (2014) bertujuan untuk menghasilkan model pembelajaran berbasis permainan tradisional untuk meningkatkan kemampuan motorik kasar anak tunagrahita ringan yang layak digunakan. Penelitian tersebut menghasilkan model pembelajaran, yaitu balap sarung, lempar karet, dorong ban, engkling, pukul balon, layang-layang, lompat tali, dan pesawat terbang.

Pendekatan bermain sebagai solusi mengenalkan teknik dasar sepak takraw diharapkan dapat memberikan manfaat bagi siswa sekolah dasar kelas atas sebagai subyek belajar, sehingga dapat memberikan sarana yang mudah untuk proses pengenalan teknik dasar. Dengan memberikan warna baru diharapkan dalam proses pembelajaran 
penjasorkes mampu membangkitkan motivasi dan minat siswa dalam mempelajari sepak takraw.

\section{METODE}

Penelitian ini merupakan penelitian dan pengembangan (Research and Development). Gall, Gall, \& Borg (2006) menyatakan bahwa, "research and development ( $R$ and $D$ ) is an insdustry-based development model in which the findings of research are use to design new products and prosedures, which then are systematically fiel-tested, evaluate, and refined until they meet specified criteria of effectivness, quality, or similar standars". Langkah-langkah penelitian terdapat dalam bagan sebagai berikut:

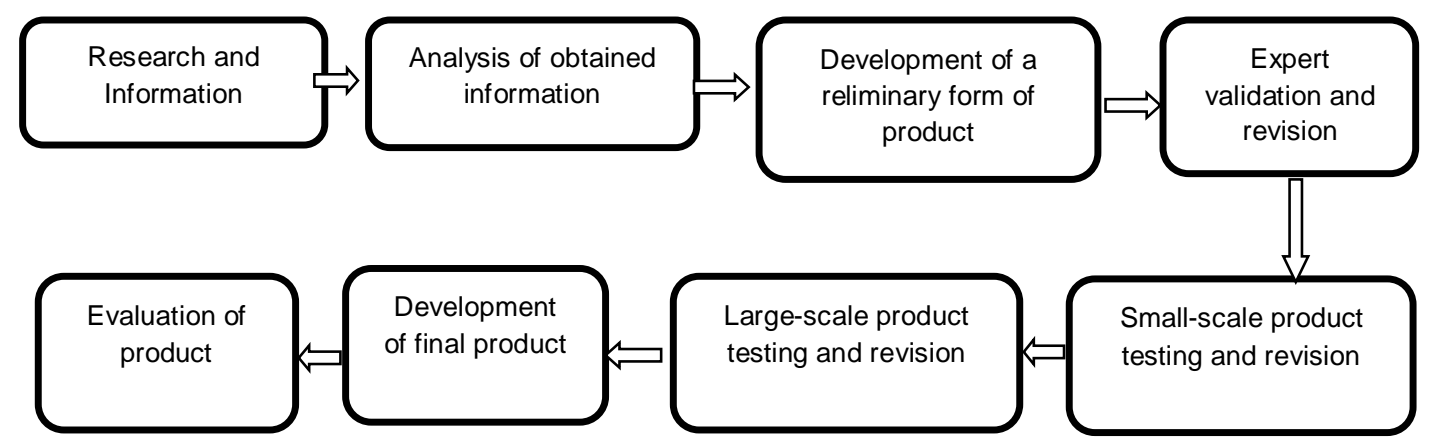

Gambar 1. Langkah-langkah dalam Penelitian Pengembangan

Hal senada juga disampaikan oleh Sugiyono (2016) yang menyatakan bahwa penelitian dan pengembangan adalah metode penelitian yang digunakan untuk menghasilkan produk tertentu, dan menguji keefektifan produk tersebut. Penelitian dan pengembangan adalah suatu proses atau langkah-langkah untuk mengembangkan suatu produk baru atau menyempurnakan produk yang telah ada, yang dapat dipertanggungjawabkan (Sukmadinata, 2012).

Pengelolaan data dalam penelitian dan pengembangan ini menggunakan analisis kualitatif dan analisis kuantitatif. Draf awal model pengenalan teknik dasar sepak takraw dengan pendekatan bermain dianggap layak untuk di ujicobakan dalam skala kecil apabila validator dalam hal ini adalah Ahli materi 1 yaitu Dosen sepak takraw UNP Kediri, 
Ahli materi 2 yaitu Dosen Manajemen Pendidikan Jasmani UNP Kediri dan Pakar Pendidikan Jasmani yaitu Guru Penjasorkes SD Negeri 1 Sukorejo dan SD Negeri Sentul 01. Dalam hal ini terdapat dua jenis nilai, yaitu hasil penilaian "Ya" mendapatkan nilai satu (1) dan hasil penilaian "Tidak" mendapatkan nilai nol (0), jika terdapat ahli materi yang berpendapat bahwa item klasifikasi tidak (nilai nol), maka dilakukan pengkajian ulang terhadap draf model pengenalan teknik dasar sepak takraw dengan pendekatan bermain yang dapat ditindak lanjuti dengan proses revisi. (Ayre \& Scally, 2014) menyatakan validasi Isi mengacu pada proses yang bertujuan untuk memberikan jaminan/keyakinan bahwa instrumen (checklist, kuesioner, atau skala) langkah-langkah daerah isi tersebut diharapkan untuk mengukur.

Adapun kisi-kisi validasi isi instrument observasi ahli materi dan praktisi sebagai berikut:

Tabel 1. Kisi-kisi validasi isi instrument observasi

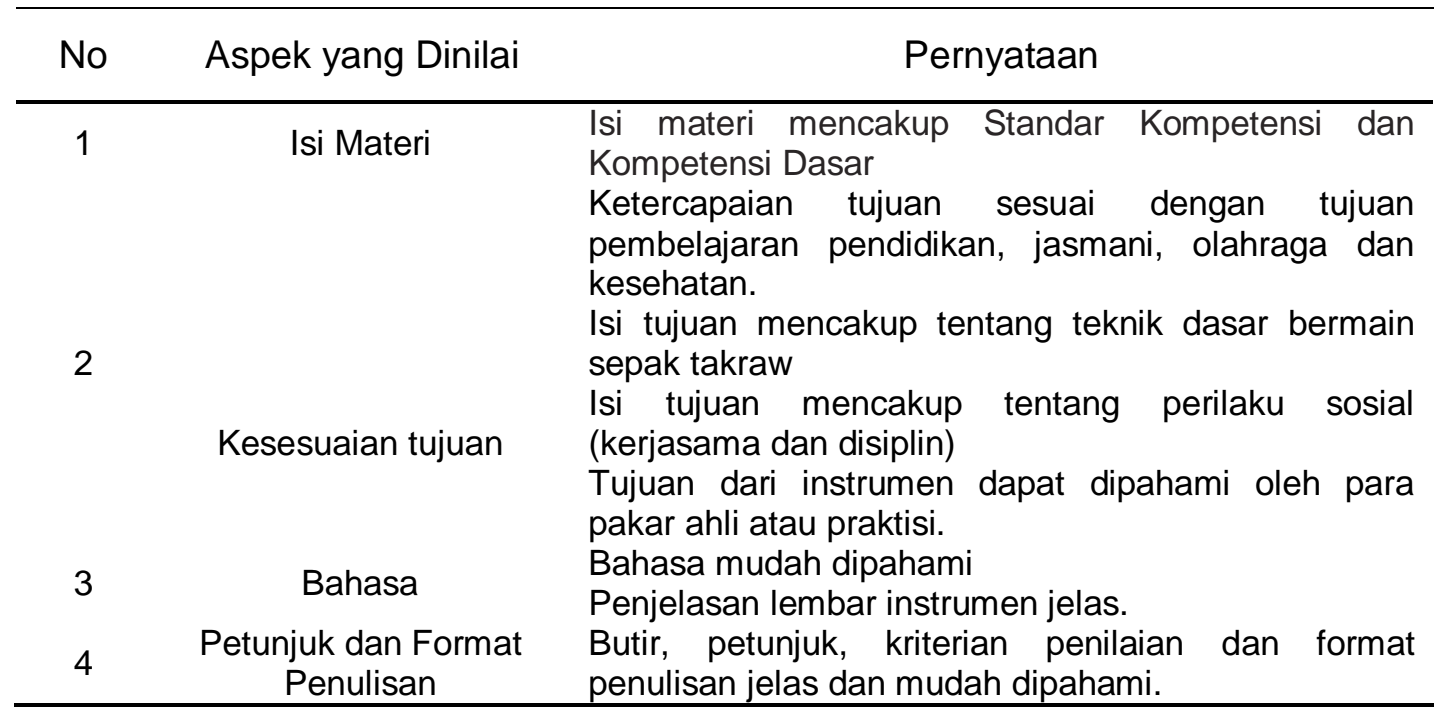

Untuk data hasil observasi model pengenalan teknik dasar sepak takraw, dan observasi keefektifan model menggunakan skala likert, dalam hal ini terdapat tiga jenis nilai yaitu hasil penilaian (1) Baik/Efektif, (2) Cukup Efektif, (3) Kurang Efektif. Hasil penilaian terhadap item-item observasi dijumlahkan, lalu total nilai dikonversikan untuk mengetahui kategorinya. Pengkorvesian nilai dilakukan dengan mengikuti standar Penilaian Acuan Patokan (PAP). Azwar (2012) menyatakan dalam 
menginterpretasikan skor mentah menjadi nilai dengan menggunakan pendekatan PAP, terlebih dahulu ditentukan kriteria nilai dan batasbatasnya, yang akan dipaparkan pada tabel 2 berikut.

Tabel 2. Pedoman Konversi Nilai

\begin{tabular}{cc}
\hline Formula & Kategori \\
\hline$X<(\mu-1,0 \sigma)$ & Kurang/Kurang Efektif \\
$(\mu-1,0 \sigma) \leq X<(\mu+1,0 \sigma)$ & Cukup/Cukup Efektif \\
$(\mu+1,0 \sigma) \leq X$ & Baik/Efektif \\
\hline
\end{tabular}

Sumber: Azwar (2012)

Data untuk mengetahui hasil peneliaian siswa maka diperlukan rubrik penilaian. Dalam penelitian ini langkah yang diambil untuk penilaian adalah pretest dan posttest yang mana prestest untuk mengetahui kemampuan awal siswa dan postest untuk mengetahui hasil setelah adanya perlakuan. Suharti \& Darisman (2017) menyatakan bahwa dalam penelitian ini mengadakan observasi sebanyak dua kali yaitu sebelum (pretest) dan sesudah (posttest). Adapun kisi-kisi rubrik penilaian sebagai berikut:

Tabel 3. Kisi-kisi Rubrik Penilaian

\begin{tabular}{cl}
\hline Aspek Diukur & \multicolumn{1}{c}{ Indikator } \\
\hline \multirow{2}{*}{ Kognitif } & Memahami aturan permainan \\
& Memahami arahan guru \\
Afektif & Kerjasama \\
& Disiplin \\
Psikomotor & Teknik dasar bermain sepak takraw \\
& Keaktifan gerak \\
\hline
\end{tabular}

Setelah diperoleh hasil dari skor awal dan skor akhir selanjutnya skor dirubah menjadi nilai. Selanjutnya dihitung selisih antara nilai pretest dan nilai posttest untuk mendapatkan nilai gain atau nila raihan (gain value). Rumus yang digunakan dalam menghitung gain score adalah: $g=\frac{\text { posttest score }- \text { pretest score }}{\text { maximum possible score }- \text { pretest score }}$

(Meltzer, 2002) 


\section{HASIL}

a. Hasil observasi skala kecil

Berdasarkan hasil tabel 4, total nilai ahli dan praktisi yaitu ahli satu (ahli pendidikan jasmani) sebesar 20 terletak pada interval $14 \leq \mathrm{X}$. Total nilai ahli dua (ahli permainan sepak takraw) sebesar 20 terletak pada interval $14 \leq \mathrm{X}$. Total nilai Praktisi (guru pendidikan jasmani) sebesar 21 terletak pada interval $14 \leq \mathrm{X}$. Dengan menggunakan batas nilai minimal dikatakan layak (valid) adalah 7. Maka, penilaian ahli materi dan praktisi terhadap aktivitas permainan dikategorikan baik (layak/valid).

Tabel 4. Hasil Observasi Skala Kecil

\begin{tabular}{ccccc}
\hline \multirow{3}{*}{ Interval } & \multirow{2}{*}{ Kategori } & \multicolumn{3}{c}{$\begin{array}{c}\text { Penilaian Ahli dan } \\
\text { Praktisi }\end{array}$} \\
\cline { 3 - 5 } & & $\mathrm{A} 1$ & $\mathrm{~A} 2$ & $\mathrm{P}$ \\
\cline { 3 - 5 } & & $\mathrm{F}$ & $\mathrm{F}$ & $\mathrm{F}$ \\
\hline $\mathrm{X}<7$ & Kurang & - & - & - \\
\hline $7 \leq \mathrm{X}<14$ & Cukup & - & - & - \\
\hline $14 \leq \mathrm{X}$ & Baik & 20 & 20 & 21 \\
\hline & Jumlah & 20 & 20 & 21 \\
\hline & Rata-rata & & 20.3 & \\
\hline & & & &
\end{tabular}

Keterangan:

A1 : Ahli Pendidikan Jasmani

A2 : Ahli Permainan Sepak Takraw

P : Guru Pendidikan Jasmani

F : Frekuensi

b. Hasil observasi skala besar

Berdasarkan tabel 5 , total nilai ahli untuk ahli dan praktisi yaitu ahli satu (ahli pendidikan jasmani) sebesar 21 terletak pada interval $14 \leq \mathrm{X}$. Total nilai ahli dua (ahli permainan sepak takraw) sebesar 21 terletak pada interval $14 \leq \mathrm{X}$. Total nilai praktisi satu (guru pendidikan jasmani) sebesar 21 terletak pada interval $14 \leq X$. Total nilai praktisi dua (guru pendidikan jasmani) sebesar 21 terletak pada interval $14 \leq X$. Dengan menggunakan batas nilai minimal dikatakan layak (valid) adalah 7. Maka, penilaian ahli materi dan praktisi terhadap aktivitas permainan dikategorikan baik (layak/valid). 
Tabel 5. Hasil Observasi Skala Besar

\begin{tabular}{cccccc}
\hline \multirow{2}{*}{ Interval } & \multirow{3}{*}{ Kategori } & \multicolumn{5}{c}{ Penilaian Ahli dan Praktisi } \\
\cline { 3 - 6 } & & $\mathrm{A} 1$ & $\mathrm{~A} 2$ & $\mathrm{P} 1$ & $\mathrm{P} 2$ \\
\cline { 3 - 6 } & Kurang & - & $\mathrm{f}$ & $\mathrm{f}$ & $\mathrm{F}$ \\
\hline $\mathrm{X}<7$ & Cukup & - & - & - & - \\
\hline $7 \leq \mathrm{X}<14$ & Baik & 21 & 21 & 21 & 21 \\
\hline $14 \leq \mathrm{X}$ & Jumlah & 21 & 21 & 21 & 21 \\
\hline \multicolumn{3}{c}{ Rata-rata } & \multicolumn{4}{c}{21} \\
\hline
\end{tabular}

Keterangan:

A1 : Ahli Pendidikan Jasmani

A2 : Ahli Permainan Sepak Takraw

P : Guru Pendidikan Jasmani

F : Frekuensi

c. Hasil Uji Efektivitas

Pengujian lapangan dari model akhir pengembangan dilakukan melalui pengamatan atau observasi. Uji efektivitas dilakukan dalam 10 pertemuan dalam mata pelajaran pendidikan jasmani. Hasil observasi dihasilkan dari pengamatan pertemuan pertama sebagai data pretest. Data pertemuan dalam pembelajaran sebagai treatment pembelajaran pendidikan jasmani. Selanjutnya hasil observasi dihasilkan dari pengamatan pertemuan terakhir sebagai data posttest. Pemaparan lengkap setelah skor mentah diubah menjadi nilai, data hasil pretest, dan posttest dapat dilihat berdasarkan per permainan, sebagai berikut:

1) Permainan Silapung

Tabel 6. Hasil Pretest dan Posttest Permainan Silapung

\begin{tabular}{ccccc}
\hline Ranah Nilai Penjas & Pretest & Posttest & Gain & Kategori \\
\hline Rata-rata Kognitif & 47.58 & 71.19 & 0.46 & Sedang \\
\hline Rata-rata Afektif & 52.46 & 70.69 & 0.49 & Sedang \\
\hline Rata-rata Psikomotor & 52.42 & 69.81 & 0.40 & Sedang \\
\hline
\end{tabular}


2) Hasil Pretest dan Postest Permainan Lajin

Tabel 7. Hasil Pretest dan Posttest Permainan Lajin

\begin{tabular}{ccccc}
\hline Ranah Nilai Penjas & Pretest & Posttest & Gain & Kategori \\
\hline Rata-rata Kognitif & 46.65 & 71.62 & 0.47 & Sedang \\
\hline Rata-rata Afektif & 45.73 & 67.81 & 0.43 & Sedang \\
\hline Rata-rata Psikomotor & 46.15 & 67.88 & 0.43 & Sedang \\
\hline
\end{tabular}

3) Hasil Pretest dan Postest Permainan Sadek

Tabel 8. Hasil Pretest dan Posttest Permainan Sadek

\begin{tabular}{ccccc}
\hline Ranah Nilai Penjas & Pretest & Posttest & Gain & Kategori \\
\hline Rata-rata Kognitif & 47.12 & 70.27 & 0.50 & Sedang \\
\hline Rata-rata Afektif & 51.96 & 70.19 & 0.45 & Sedang \\
\hline Rata-rata Psikomotor & 51.42 & 68.88 & 0.40 & Sedang \\
\hline
\end{tabular}

4) Hasil Pretest dan Postest Permainan Halo

Tabel 9. Hasil Pretest dan Posttest Permainan Halo

\begin{tabular}{ccccc}
\hline Ranah Nilai Penjas & Pretest & Posttest & Gain & Kategori \\
\hline Rata-rata Kognitif & 51.50 & 71.69 & 0.51 & Sedang \\
\hline Rata-rata Afektif & 45.54 & 69.27 & 0.49 & Sedang \\
\hline Rata-rata Psikomotor & 45.58 & 69.12 & 0.45 & Sedang \\
\hline
\end{tabular}

5) Hasil Pretest dan Postest Permainan Lasun

Tabel 10. Hasil Pretest dan Posttest Permainan Lasun

\begin{tabular}{ccccc}
\hline Ranah Nilai Penjas & Pretest & Posttest & Gain & Kategori \\
\hline Rata-rata Kognitif & 45.08 & 70.23 & 0.51 & Sedang \\
\hline Rata-rataAfektif & 46.04 & 69.31 & 0.47 & Sedang \\
\hline Rata-rata Psikomotor & 45.73 & 67.54 & 0.41 & Sedang \\
\hline
\end{tabular}

Berdasarkan hasil dari keenam tabel di atas diketahui rerata nilai kognitif untuk nilai posttest lebih besar dari nilai pretest, dan nilai gain skor menunjukkan kategori sedang. Rerata nilai afektif untuk nilai posttest lebih besar dari nilai pretest, dan nilai gain skor menunjukkan kategori sedang. Rerata nilai psikomotor untuk nilai posttest lebih besar dari nilai pretest, dan nilai gain skor menunjukkan kategori sedang. Disimpulkan bahwa berdasarkan tujuan pendidikan jasmani dengan ranah kognitif, afektif, dan psikomotor, keenam model permainan dikategorikan sedang. 


\section{PEMBAHASAN}

Penelitian ini terdapat produk lima model permainan yang dikembangkan berdasarkan teknik dasar sepak takraw antara lain teknik sepak sila dengan nama permainan silapung, teknik sepak kura dengan nama permainan lajin, teknik sepak badek dengan nama permainan sadek, teknik memaha dengan nama permainan halo, dan teknik heading dengan nama permainan lasun. Berikut hasil penilai ahli materi dan praktisi dalam model pengenalan teknik dasar sepak takraw pada anak sekolah dasar kelas atas.

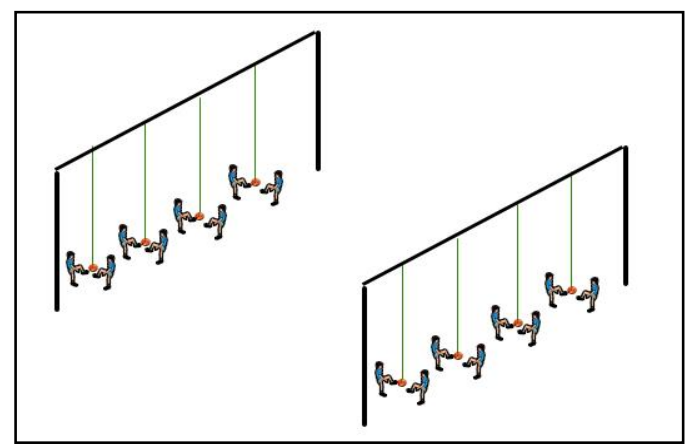

1. Model Permainan Silapung

a. Cara melakukan:

Setiap kelompok menendang ataupun menimang bola sesuai kehendak siswa tanpa ada batasan.

Gambar 2. Permainan Silapung

b. Tujuan permainan:

1) Aspek psikomotor mengenalkan teknik dasar sepak takraw (sepak sila, sepak mula, sepak kuda, sepak badek, memaha, heading),

2) Aspek afektif meningkatkan komunikasi, kerjasama, dan percaya diri anak,

3) Aspek kognitif mengetahui kemampuan anak dalam menguasai bola 


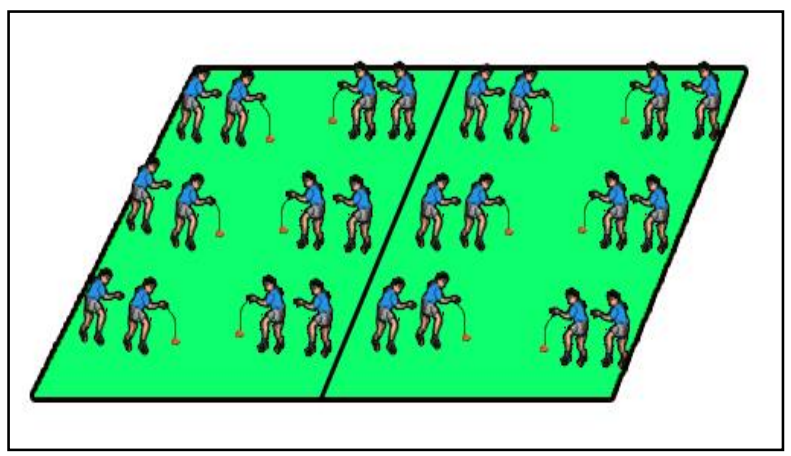

2. Model Permainan Lajin

a. Cara melakukan:

1) Setiap kelompok mendapatkan bola yang diikat dengan tali,

Gambar 3. Permainan Lajin

2) Secara bergantian, siswa melakukan ball feeling dengan bola yang diikat dengan tali dan dipegang sendiri, dan

3) Siswa mempraktekkan teknik dasar sepak takraw (sepaksila, sepakmula, sepakkuda, sepakbadek, memaha, heading) dengan menggunakan bola yang ditali tersebut.

b. Tujuan permainan:

1) Aspek psikomotor meningkatkan keterampilan teknik dasar (sepaksila, sepakmula, sepakkuda, sepakbadek, memaha, heading),

2) Aspek kognitif mengetahui kemampuan anak dalam menguasai bola,

3) Aspek afektif meningkatkan rasa percaya diri, kerja keras, dan tekun.

\section{Model Permainan Sadek}

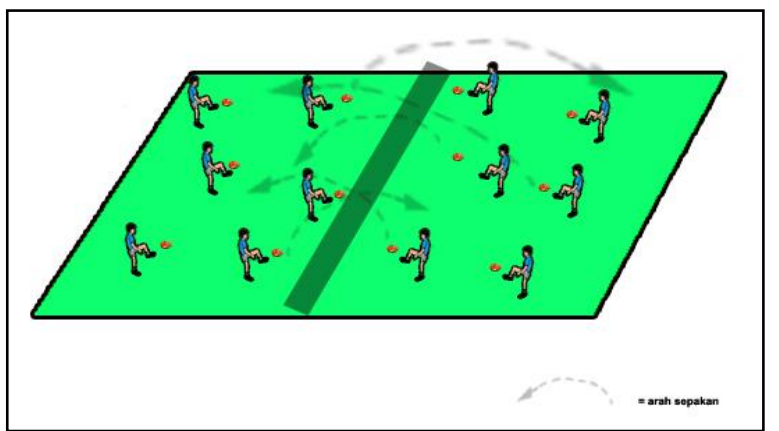

Gambar 4. Permainan Sadek a. Cara Melakukan

1) Siswa harus menyepak menyeberang net dan masuk ke dalam daerah lawan,

2) Siswa yang menerimabola dari lawan boleh ditangkap dengan tangan atau bisa langsung dikembalikan dengan teknik yang sesuai

3) Bola datang dari regu lawan harus segera dikembalikan dan tidak 
boleh ditunggu sampai bola banyak.

b. Tujuan permainan:

1) Aspek kognitif meningkatkan akurasi sepakan,

2) Aspek psikomotor meningkatkan teknik dasar (sepak sila, sepak mula, sepak kuda, sepak badek, memaha, heading),

3) Aspek afektif melatih kerja keras, kesabaran, sportif, dan daya juang yang tinggi.

4. Model Permainan Halo

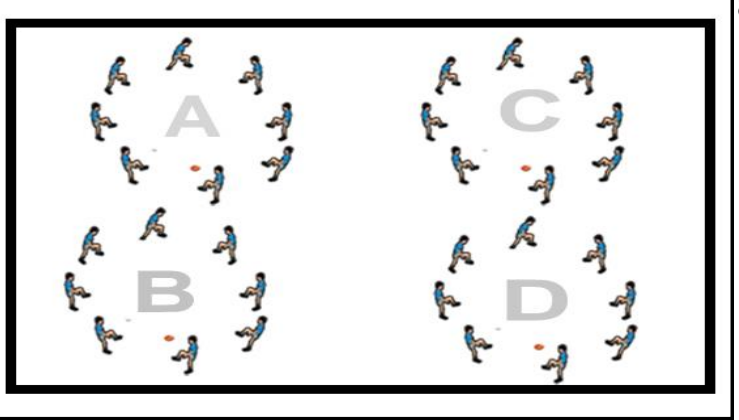

Gambar 5. Permainan Halo a. Cara melakukan:

Setiap sepakan atau teknik dasar lainnya dihitung satu poin. Setiap siswa maksimal melakukan tiga sepakan dilanjutkan dioper kepada temannya.

b. Tujuan permainan antara lain:

1) Aspek kognitif siswa mengetahui ball feeling terhadap bola yang bergerak,

2) Aspek psikomotor meningkatkan teknik dasar (sepaksila, sepakmula, sepakkuda, sepakbadek, memaha, heading),

3) Aspek afektif meningkatkan komunikasi dengan anggota kelompok.

5. Model Permainan Lasun

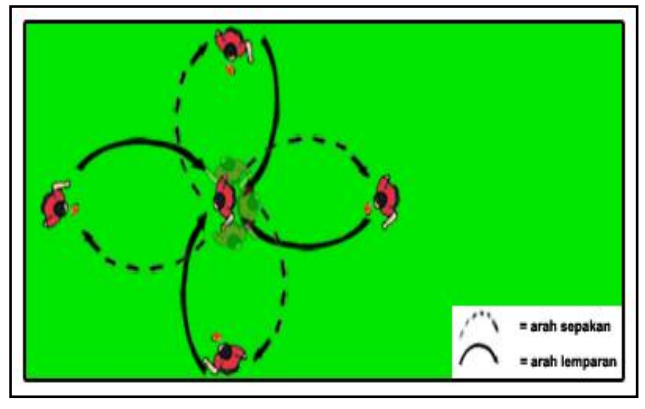

Gambar 6. Permainan Lasun a. Cara melakukan:

1) Anak yang membawa bola memanggil nama anak yang di tengah kemudian anak yang di tengah lingkaran berusaha untuk menguasai ataupun langsung mengembalikan bola kepada pelempar, 
2) Pergantian pemain di tengah dilakukan jika sudah dapat megembalikan bola dari semua pelempar.

b. Tujuan permainan:

1) Aspek kognitif meningkatkan reaksi terhadap datangnya bola,

2) Aspek psikomotor meningkatkan teknik dasar (sepak sila, sepak mula, sepak kuda, sepak badek, memaha, heading),

3) Aspek afektif meningkatkan komunikasi dengan anggota kelompok.

Dari lima model permainan yang dibuat diatas tujuannya adalah untuk mengembangkan aspek kognitif, aspek afektif, dan aspek psikomotor. Aspek psikomotor berhubungan dengan gerak lokomotor, non lokomotor dan manipulative. Menurut Lumintuarso (2013) mengatakan bahwa gerak multilateral merupakan penggabungan dari berbagai gerak dasar (gerak lokomotor, non lokomotor, dan manipulatif) dan dasar gerak keterampilan olahraga.

\section{KESIMPULAN}

Pendekatan bermain sebagai solusi dalam mengenalkan teknik dasar sepak takraw sangat efektif dan layak digunakan untuk siswa sekolah dasar kelas atas. Terdapat 6 model permainan yang telah diujikan. Pembelajaran pengenalan teknik dasar sepak takraw untuk anak sekolah dasar kelas atas yang layak digunakan, maka dilakukan penelitian pengembangan dengan langkah-langkah pada tahap pra-pengembangan yaitu melakukan kajian literature, penelitian relevan dan studi pendahuluan. Untuk tahap pengembangan yaitu penyusunan draft model (prototype), validasi ahli, uji coba skala kecil, uji coba skala besar dan hasil dari pengembangan berupa produk.

Saran pemanfaatan berdasarkan penelitian dan pengembangan ini yaitu model pembelajaran dengan pendekatan bermain untuk siswa sekolah dasar kelas atas dapat mencapai tujuan pendidikan jasmani yaitu untuk mengembangkan aspek kognitif, aspek afektif, dan aspek psikomotor. Keenam model permainan ini dapat digunakan oleh Guru 
Penjasorkes dalam pembelajaran sepak takraw dimana melalui aktivitas yang menyenangkan sehingga dapat memperkaya pengalaman dan meningkatkan kemampuan gerak anak, guna membentuk generasi muda yang berprestasi, berkualitas, dan berkarakter.

\section{REFERENSI}

Ardiyanto, A., \& Sukoco, P. (2014). Pengembangan Model Pembelajaran Berbasis Permainan Tradisional untuk Meningkatkan Kemampuan Motorik Kasar Anak Tunagrahita Ringan. Jurnal Keolahragaan. https://doi.org/10.21831/jk.v2i2.2608

Ayre, C., \& Scally, A. J. (2014). Critical values for Lawshe's content validity ratio: Revisiting the original methods of calculation. Measurement and Evaluation in Counseling and Development. https://doi.org/10.1177/0748175613513808

Azwar, S. (2012). Penyusunan Skala Psikologi. Yogyakarta: Pustaka Pelajar.

Chueachot, S., Srisa-Ard, B., \& Srihamongkol, Y. (2013). The development of an assessment for learning model for elementary classroom. International Education Studies. https://doi.org/10.5539/ies.v6n9p119

Datta, P. P. A. K., \& Purashwani, M. (2010). Construction of Norms for Skill Test Table Tennis Players. International Journal of Table Tennis Sciences.

Gall, M. D., Gall, J. P., \& Borg, W. R. (2006). Educational Research: An Introduction, 8th Edition. Educational An Introduction.

John Wiley and Sons. (2012). Coaching sience (Theory into practice). England: British library.

Juniarta, T., \& Siswantoyo, S. (2014). Pengembangan Model Permainan Rintangan (Handicap Games) untuk Latihan Kebugaran Jasmani Anak Usia 10-12 Tahun. Jurnal Keolahragaan. https://doi.org/10.21831/jk.v2i1.2606

Kurdi, K., \& Sukadiyanto, S. (2014). Pengembangan Model Pembelajaran Motorik dengan Pendekatan Bermain Menggunakan Agility Ladder untuk Anak Sekolah Dasar. Jurnal Keolahragaan. https://doi.org/10.21831/jk.v2i2.2625.

Lumintuarso, R. (2013). Pembinaan multilateral bagi atlet pemula (pedoman latihan dasar bagi atlet muda berbakat). Yogyakarta: UNY Press.

Meltzer, D. E. (2002). The relationship between mathematics preparation and conceptual learning gains in physics: A possible "hidden variable" in diagnostic pretest scores. American Journal of Physics. https://doi.org/10.1119/1.1514215 
Mohnsen, B. S. (2008). Teaching middle school physical education. United States: Human Kinetics.

Ngatiyo. (2008). Membelajarkan anak usia dini melalui bermain. Jurnal Cakrawala Kependidikan Pontianak: Universitas Tanjungpura., 6(2).

Payne, V. G., \& Isaacs, L. D. (2011). Human Motor Development: A LifeSpan Approach. In Human Motor Development: https://doi.org/10.4324/9781315213040

Scharf, M., \& Mayseless, O. (2009). Socioemotional characteristics of elementary school children identified as exhibiting social leadership qualities. Journal of Genetic Psychology. https://doi.org/10.3200/GNTP.170.1.73-96

Simamora, R. H. (2009). Buku ajar pendidikan dalam keperawatan (K. EGC, ed.). Jakarta: (IKAPI).

Sugiyono, P. D. metode penelitian kuantitatif, kualitatif,dan R\&D. , Alfabeta, cv. (2016).

Suharti, S., \& Darisman, E. K. (2017). Pengaruh Senam Semangat Pagi (SSP) Terhadap Peningkatan Kebugaran Siswa Kelas XI SMAN 4 Sidoarjo. Jurnal SPORTIF: Jurnal penelitian Pembelajaran. https://doi.org/10.29407/js_unpgri.v3i2.11894

Sukmadinata, N. S. (2012). Kurikulum dan Pembelajaran Kompetensi. Bandung: PT Refika Aditama.

Sun, H. (2013). Impact of exergames on physical activity and motivation in elementary school students: A follow-up study. Journal of Sport and Health Science. https://doi.org/10.1016/j.jshs.2013.02.003

Utami, N. S., \& Sukadiyanto, S. (2014). Model Pengenalan Air Bagi Siswa Taman Kanak-Kanak. Jurnal Keolahragaan. https://doi.org/10.21831/jk.v2i2.2626

Zetou, E., Papadakis, L., Vernadakis, N., Derri, V., Bebetsos, E., \& Filippou, F. (2014). The Effect of Variable and Stable Practice on Performance and Learning the Header Skill of Young Athletes in Soccer. Procedia - Social and Behavioral Sciences. https://doi.org/10.1016/j.sbspro.2014.09.328 